\title{
Roberto SCHWARZ E A DESATIVAÇÃO DA UNIVERSALIDADE DO BRÁS CUBAS
}

ROBERTO SCHWARZ AND THE DEACTIVATION

OF THE UNIVERSALITY OF BRÁS CUBAS

Elvis Paulo Couto

ORCID 0000-0002-2570-3875

Universidade Estadual Paulista Júlio de Mesquita Filho

Araraquara, SP, Brasil

\section{Resumo}

O objetivo deste artigo é questionar a validade de um dos argumentos de Roberto Schwarz em Um mestre na periferia do capitalismo: Machado de Assis. Nesta obra, o crítico contrapóe-se frontalmente à possibilidade de investigação das Memórias póstumas de Brás Cubas a partir de um viés universalista, apresentando, ao invés disso, uma análise marxista centrada no processo de formalização da conduta da classe dirigente brasileira à época do Império. Alguns apontamentos dos principais representantes da fortuna crítica machadiana são usados para refutar a tese de que somente a interpretação histórico-sociológica é capaz de descortinar o sentido do primeiro romance moderno brasileiro.

Palavras-chave: Roberto Schwarz, Memórias póstumas de Brás Cubas, Universalidade, Crítica machadiana

\begin{abstract}
The purpose of this paper is to question the validity of one of Roberto Schwarz's arguments in $A$ master on the periphery of capitalism: Machado de Assis. In this work, Schwartz directly opposes the possibility of investigating The posthumous memoirs of Brás Cubas from a universalist point of view, presenting, instead, a Marxist analysis centered on the process of formalization of the conduct of the Brazilian ruling class at the time of the Empire. Some notes from the main representatives of Machado's critical fortune are used to refute the thesis that only an historical-sociological
\end{abstract}

\section{Résumé}

Cet article vise à questionner la validité d'un des arguments de Roberto Schwarz dans Um mestre na periferia do capitalismo: Machado de Assis. À cette oeuvre, le critique s'oppose frontalement à la possibilité de recherche sur les Mémoires posthumes de Brás Cubas à partir d'un point de vue universaliste, en présentant, par contre, une analyse marxiste centrée sur le processus de formalisation de la conduite de la classe dominante brésilienne à l'époque de l'Empire. Certaines notes des principaux représentants de la fortune critique de Machado de Assis sont utilisées pour réfuter la thèse selon 
interpretation can reveal the meaning of the first modern Brazilian novel.

Keywords: Roberto Schwarz, Posthumous memoirs of Brás Cubas, Universality, Machado de Assis criticism laquelle l'intérpretation historique et sociologique est l'unique capable de découvrir le sens du premier roman moderne brésilien.

Mots-clés: Roberto Schwarz, Mémoires posthumes de Brás Cubas, Universalité, Critique de Machado de Assis

Desde a sua publicação, em 1880, as Memórias póstumas de Brás Cubas, de Machado de Assis, suscitam polêmica. A fortuna crítica dessa obra, após mais de um século de acumulação de interpretaçóes, é marcada por debates que continuam acalorados. Este artigo visa a intervir numa das discussóes que ainda está longe de convergir para um consenso, qual seja, a incompatibilidade que existe entre a crítica universalista, que julga o valor do primeiro romance da fase madura de Machado pelo seu aspecto internacionalmente apreciável, isto é, pela sua qualidade estilística e sua densidade psicológico-filosófica, e a crítica localista de Roberto Schwarz, centrada na ideia de que só é possível compreender adequadamente o sentido do discurso narrativo machadiano se se conhecem os problemas inerentes ao processo de formação da sociedade brasileira.

Em Um mestre na periferia do capitalismo, Roberto Schwarz (2000, p. 174, grifos nossos) desativa o mecanismo universalista de interpretação das Memórias póstumas de Brás Cubas, de Machado de Assis: "Não especulemos sobre os motivos que levaram Machado a preferir uma composição escorregadia, onde a clarividência ferina em matéria histórico-social vem unida à formulação inespecifica, universalista, em descompasso com o objeto designado." Como se vê, ao invés de representar com verossimilhança os problemas históricosociológicos - aqueles ligados à herança colonial, ao escravagismo, ao paternalismo e ao clientelismo -, Machado preferiu representá-los de maneira "escorregadia", isto é, em acordo com o aspecto da volubilidade, que acaba por encobrir o "objeto designado" - o comportamento de classe - com o véu dos temas universais, a-históricos, metafísicos e de cunho fantástico.

Trata-se, segundo Schwarz (2000, p. 174, grifo nosso), de "uma forma dotada de vasto alcance, cujo perigo está na derrapagem metafísica." Observe-se que Schwarz fala em "perigo": não é por meio da abordagem metafísica que se deve procurar compreender o discurso narrativo das Memórias, pois o verniz metafísico do livro visa apenas a ironicamente encobrir o essencial: a conduta elitista. Os temas transcendentais relativos à natureza humana não receberiam de Brás tratamento universalista, mas localista: "Trata-se literalmente da universalização dos esquemas de conduta da classe dominante brasileira.” 
(SCHWARZ, 2000, p. 174). Brás teria versado enciclopedicamente sobre as questóes da existência humana de modo irrisório, em conformidade com o padrão mesquinho e classista de sua percepção. Assim, o romance apresentaria tentativas excêntricas de universalização dos modos iníquos de sociabilidade.

Isso fica mais claro com a seguinte afirmação: "Machado é o romancista da desfaçatez das elites brasileiras, e não do 'homem em geral', como frequentemente se diz." (SCHWARZ, 1999, p. 222, grifos nossos). Perceba-se que Schwarz - ele está referindo-se exclusivamente às Memórias - exclui o viés universalista de análise que foi gravemente explorado pela fortuna crítica machadiana. Todavia, se levarmos em consideração a clássica passagem de Machado de Assis (1910, p. 14, grifos nossos), segundo a qual "o que se deve exigir do escritor, antes de tudo, é certo sentimento íntimo, que o torne homem do seu tempo e do seu país, ainda quando trate de assuntos remotos no tempo e no espaço", perceberemos na citada formulação de Schwarz, salvo engano, uma deformação do pensamento de Machado acerca do ofício de escritor. Por que os "assuntos remotos no tempo e no espaço", quando tratados - mesmo que risivelmente - por um "homem do seu tempo e do seu país", isto é, atento aos problemas locais, deixam de ser temas universais para figurarem apenas como "desacerto entre as relaçóes sociais do país e os quadros ideológicos do mundo burguês"? (SCHWARZ, 2000, p. 174). Quando Schwarz (2000, p. 176) afirma que "a psicologia universalista, com a sua dicção impregnada de racionalismo clássico francês, naturalmente serve à vaidade social", poderíamos questionar: tal "vaidade social" é característica apenas da classe dominante brasileira? Ela não seria também um atributo universal do comportamento humano?

O problema não está em interpretar-se à luz do marxismo a volubilidade - uma fórmula analítica profícua -, mas em inviabilizar-se qualquer interpretação que não seja marxista, como se o romance não se prestasse à ambiguidade: "Como interpretar as palavras de um narrador mal-intencionado, cuja volubilidade se governa por conveniências e inconveniências de uma posição de classe? Considerá-las fora deste viés prático, e da leitura questionadora que em princípio lhe corresponde, só as pode banalizar." (SCHWARZ, 2000, p. 177, grifos nossos). Seria adequado dizer-se que a crítica de Augusto Meyer, ao esquadrinhar, sob o prisma universalista, o movimento volúvel da narração, banalizou-o? Sobre esse movimento, diz Meyer (1958, p. 13): "há nele uma letargia indefinível, a sonolência do homem trancado em si mesmo, espectador de si mesmo, incapaz de reagir contra o espetáculo da sua vontade paralisada, gozando até com lucidez a própria agonia." Se, para Schwarz, o narrador das Memórias dá vazão à sua vontade arbitrária porque a sua situação de classe permite-lhe assim proceder, para Meyer (1958, p. 16-17), essa arbitrariedade volitiva, que ironiza quase todas as questóes universais, não deixa de ser universal, é própria do homem: 
Havia em Machado de Assis esse amor vicioso que caracteriza o monstro cerebral, a volúpia da análise pela análise, mas havia também - e nisto vejo o seu drama - a consciência da miséria moral a que estava condenado por isso mesmo, a esterilidade quase desumana com que o puro analista paga o privilégio de tudo criticar e destruir.

O "privilégio de tudo criticar e destruir", visto por Meyer como traço comportamental do protagonista que almeja submeter o mundo ao crivo do ceticismo e à constatação da inexistência de sentido na vida, é, para Schwarz (2012a, p. 255, grifos do autor), uma prerrogativa de classe:

É como se Brás Cubas dissesse que a cultura e a civilidade, que preza e de que considera parte, podiam funcionar à maneira dele, e náo o impediriam de dar curso a seus privilégios. Ou, ainda, como se demonstrasse, pelo escândalo e na prática, operando sobre o corpo consagrado da cultura universal, as consequências daqueles mesmos privilégios. Assim, longe de trocar um mundinho irrelevante (porém nosso) pela universalidade prestigiosa (mas falsificada) do ser-ou-náo-ser das formas, Machado associava os dois planos, de modo a desbloquear, em espírito de exposição crítica, o universo sequestrado que havia sido o seu ponto de partida.

A universalidade do romance machadiano, portanto, estaria subordinada à condição de classe: Brás Cubas, ao mesmo tempo, atribuiria caráter universal às suas práticas ignóbeis e adequaria o legado universalmente prestigiado da cultura civilizada às normas da classe proprietária oitocentista. De qualquer modo, segundo Schwarz, "o universo sequestrado" (as questóes intelectuais, filosóficas e morais de cariz universal) seria desbloqueado por Machado, isto é, adquiriria feição abrasileirada, caricatural. Em suma: o narrador das Memórias não falaria do "homem em geral", mas do proprietário brasileiro de terras e de escravos. O olhar crítico de Machado estaria fixado na atuaçáo da classe dominante e não no homem eterno.

As seguintes perguntas são inevitáveis: o conceito de classe - central na teoria marxista - é indispensável ao descortínio do sentido das Memórias? A volubilidade é somente um caráter de classe? $\mathrm{O}$ autor de Um mestre não estaria incorrendo em reducionismo ao cancelar a perspectiva universalista em nome da interpretação marxista?

Uma resposta a essas perguntas poderia ser dada por Antonio Candido, que interpreta o conjunto da obra machadiana conforme os critérios universais que foram invalidados por Schwarz. Segundo Candido (2004, p. 27), a questão central nas Memórias é a seguinte: 
[...] se a fantasia funciona como realidade; se não conseguimos agir senão mutilando o nosso eu; se o que há de mais profundo em nós é no fim de contas a opiniáo dos outros; se estamos condenados a não atingir o que nos parece realmente valioso, qual a diferença entre o bem e o mal, o justo e o injusto, o certo e o errado? Machado de Assis passou a vida ilustrando esta pergunta, que é modulada de maneira exemplar no primeiro e mais conhecido dos seus grandes romances de maturidade: Memórias póstumas de Brás Cubas.

Nada mais universalista do que essa visão, como ratifica Alfredo de Melo (2014, p. 410): "o crítico [Candido] faz uma leitura do principal romancista brasileiro em chave universalista." A tese de Um mestre vai de encontro ao estudo de Candido em "Esquema de Machado de Assis": "Os temas estudados por Candido na ficção machadiana são todos eles universais, filosofantes e abstratos" (MELO, 2014, p. 410, grifos nossos). Sobre a nunca pronunciada discordância de ponto de vista acerca da obra de Machado, diz Melo (2014, p. 410, grifos nossos):

Trata-se de um silêncio intrigante, afinal, Schwarz estuda Machado de Assis desde os inícios dos anos 1960, questionando a visão universalista de Machado e mostrando o quanto a forma literária do romance machadiano, sobretudo Memórias póstumas de Brás Cubas, marcado pela volubilidade do narrador, articula uma constelação ideológica muito própria de um país periférico como o Brasil.

Talvez se ache o equilíbrio entre as duas posiçóes contrastantes - a do localismo e a do cosmopolitismo - aceitando ambas como válidas, pois cada uma delas explora uma dimensão fértil do romance machadiano, ainda que, para Schwarz (2012b, p. 13), a dimensão histórica seja a única capaz de desvendar adequadamente o significado das Memórias. Assim ele explica o salto positivo da fase inicial para a fase de maturidade: "Em lugar do pesquisador das constantes da alma humana, acima e fora da história, indiferente às particularidades e aos conflitos do país, entrava um dramatizador malicioso da experiência brasileira." Como se pode notar, o "pesquisador das constantes da alma humana" sai de cena, não mais se apresenta na etapa realista da ficção machadiana, em que surge, por assim dizer, o historiador das relações de classe.

Lúcia Miguel Pereira (1988, p. 192, grifos nossos), ao entrevistar a viúva do escritor Mário de Alencar, amigo de Machado, colheu o seguinte depoimento: "A Mário de Alencar, que lhe [a Machado] perguntou um dia como, depois de ter escrito Helena, pôde escrever o Brás Cubas, explicou o romancista que se modificara porque perdera todas as ilusóes sobre os homens." A justificativa da superioridade das Memórias em relação à ficção anterior, proferida pelo próprio autor, indica a passagem de uma visão edificante para 
uma visão pessimista e descrente das qualidades morais do ser humano. Diante disso, somente teria validade o argumento schwarziano que sugere, embora acertadamente, a adoção de uma perspectiva crítica sobre as relaçóes sociais e as humilhações de classe que elas comportam? A explicação de caráter universalista, centrada nos problemas inerentes à moral e à psicologia, concedida por Machado e desenvolvida por Lúcia Miguel Pereira - e que diz respeito ao "homem em geral" - seria subalterna à explicação históricosociológica?

Aderindo ao método crítico-biográfico, largamente explorado por Sainte-Beuve, Lúcia Miguel Pereira fez observaçóes sobre Brás Cubas que, confrontadas com a argumentação de Schwarz, seriam falsas por não enxergarem nessa figura o proprietário que coopta os clientes conforme a variabilidade de seu humor e cuja reflexão fantasiosa e volátil é autorizada pela classe ociosa de que faz parte. Porém, não são epistemologicamente frágeis as seguintes afirmaçóes, visto que elas sintetizam certos aspectos universais da condição humana recorrentes nas ponderaçóes do narrador das Memórias: 1) "observada em si mesma, a agitação humana tem uma aparência de inutilidade que a torna burlesca" (PEREIRA, 1988, p. 193); 2) a "sensação de falta de sentido da vida, misturada a um sentimento de compaixão pelos vãos esforços dos homens, fez de Machado de Assis o grande romancista e o grande humorista que se revelou no Brás Cubas" (PEREIRA, 1988, p. 193); 3) "observando os outros, percebeu o vazio da agitação humana” (PEREIRA, 1988, p. 195); 4) "gastou os seus dias todos [...] numa autoanálise estéril e empolgante" (PEREIRA, 1988, p. 195); 5) "vingava-se da sua incapacidade para viver, mofando do mundo com 'um prazer satânico" (PEREIRA, 1988, p. 195); 6) "a falta de sentido da vida dá a vontade de se 'debruçar sobre o abismo do Inexplicável”" (PEREIRA, 1988, p. 197).

Michael Wood (2006), em artigo sobre a obra de Machado de Assis, intitulado "Master among the ruins", contesta o reducionismo historicista da crítica schwarziana. No texto "Leituras em competição", Schwarz (2012b, p. 16) propóe-se a responder às seguintes perguntas formuladas por Wood: "seria preciso interessar-se pela realidade brasileira para apreciar a qualidade da ficção machadiana? Ou ainda, a peculiaridade de uma relação de classe, mesmo que fascinante para o historiador, não será 'um tópico demasiado monótono para dar conta de uma obra-prima?"”

Para Schwarz (2012b, p. 22), haveria incorreção no modo de questionar de Wood, que se teria baseado no seguinte paradoxo: "o sucesso internacional viria de mãos dadas com o desaparecimento da particularidade histórica, e a ênfase na particularidade histórica seria um desserviço prestado à universalidade do autor." Registre-se que Schwarz insiste na relação excludente entre os pontos de vista: a internacionalização da obra machadiana implicaria a negação de 
sua historicidade, ao passo que o desvendamento de seu substrato histórico torná-la-ia provinciana e pitoresca aos olhos estrangeiros. No entanto, foi justamente o elemento universalista que a elevou à estatura internacional: a composição machadiana não versa somente sobre o homem brasileiro, ela dialoga com o homem sem adjetivos. Não podemos reduzir a análise ao condicionamento de classe, afirmando que Machado olhava apenas para ele, mesmo quando tratava "de assuntos remotos no tempo no espaço." Antes de Schwarz descortinar legitimamente o aparato objetivo (ou prático, como ele comumente diz) do primeiro grande romance brasileiro, as Memórias eram apreciadas e prestigiadas, inclusive internacionalmente, haja vista que Helen Caldwell publicou um estudo sobre elas, inserido em Machado de Assis: the Brazilian master and his novels, em 1970 (sete anos antes de Schwarz publicar o seu). Não se pode invalidar o caráter de obra aberta do livro. O fato de estarmos discutindo sobre "leituras em competição" atesta a ambiguidade do romance: ele fala sobre a História e as relaçôes sociais brasileiras, mas também sobre as perturbaçóes psicológicas do ser, a insignificância da vida, a loucura etc.

"O artista entra para o cânon, mas não o seu país." (SCHWARZ, 2012b, p. 22). Essa afirmação, argumentando contra o universalismo proposto por Wood, sugere que, ao evidenciar-se a peculiaridade histórica de uma obraprima, ela ganha prestígio e o seu país também. Entender-se, por meio da leitura do texto, o problema da escravidáo e da cooptação, as incongruidades do liberalismo, o autoritarismo da classe dirigente, significa adquirir-se uma percepção crítica sobre a nação brasileira — um avanço, portanto, na consciência histórica daqueles que têm contacto com o texto machadiano e com a crítica schwarziana. Contudo, o refinamento da noçáo histórica, isto é, a obtenção de uma visão negativa sobre a sociedade brasileira, não a faz entrar "para o cânon": nosso passado colonial e escravocrata continua a enodoar a nossa História. O que fez Machado alçar voo foi justamente a sua capacidade de fazer confluir, no processo de formalização literária, a estrutura histórico-sociológica, as questôes psicológicas universalizantes e o humorismo filosofante. Na verdade, é a universalidade de sua escrita representada pelas questôes nacionais que permitiu às letras brasileiras subirem ao patamar de país desenvolvido no campo da cultura e das ideias. Cabe aqui a citação de Sérgio Buarque de Holanda (1996, p. 35): "a independência intelectual de um povo não requer a emancipação política."

Na mesma esteira reflexionante de Wood, Abel B. Baptista (2009, p. 81) afirma que "Schwarz considera-se o terminus ad quem de uma linha de leitura que, lenta mas progressivamente, devolveu o verdadeiro Machado ao Brasil, resgatando-o de décadas de fortuna crítica irrelevante." A leitura correta, para Schwarz, não seria a estrangeirizante, ávida de mostrar um Machado 
alheio aos problemas sociais do Brasil, mas aquela que visse nele um escritor que retomou, sob ângulo crítico, os problemas ideológicos representados com naturalidade nos romances dos escritores que o precederam. No entanto, para Baptista (2009, p. 83), o crítico brasileiro não percebe que "a originalidade das Memórias póstumas de Brás Cubas" reside "na ligaçáo, inusitada, entre a forma livre e a filosofia." Mais do que isso: segundo Baptista (2009, p. 83), Schwarz passa ao largo da principal questáo do livro, que qualquer "leitor competente" se coloca: "por que cómico, se sombrio, por que sombrio, se cómico?" Veja-se que, de acordo com esse ponto de vista, o problema da originalidade do romance não será sequer tocado se se tentar explicá-la pelo raciocínio segundo o qual Machado foi pioneiro ao formalizar criticamente o descompasso ideológico próprio à ex-colônia.

Como é sabido, Antonio Candido sustenta o argumento, na Formação da literatura brasileira, de que a nossa emancipação literária ocorreu com a publicaçáo das Memórias póstumas. A explicação do autor para a superioridade machadiana encontra-se na direçáo oposta à de Schwarz, pois apresenta a justificativa de que essa evolução literária se deve à transcendência do localismo em direção ao universalismo:

[...] as sendas poéticas do Indianismo e a humanidade sincera mas superficial do regionalismo não eram elementos suficientes para a maturidade do nosso romance. Faltavam-lhe para isso aquelas "pesquisas psicológicas", que segundo Lúcia Miguel Pereira constituem o brasão de Machado de Assis [...]. Elas consistem, principalmente, em recusar o valor aparente do comportamento e das ideias, em não aceitá-los segundo a norma que lhes traçam o costume, ou os seus desvios mais frequentes. Há na pesquisa psicológica uma certa malícia e uma certa dor, que levam o romancista a esquadrinhar a composiçáo dos atos e pensamentos; a reconstituir as maneiras possíveis por que teriam variado, levando-os, muitas vezes, a consequências inaceitáveis para a visão normal. (CANDIDO, 2007, p. 529, primeiros grifos nossos, último grifo do autor).

O raciocínio de Candido é claro: a desprovincianização de nossas letras, assimilada com maestria por Machado, está na profundidade da análise psicológica que transcende "a visão normal', isto é, que recusa a visão comum à determinada cultura para lograr a essência das tendências e dos comportamentos universais.

Admitindo-se, como Candido (2007, p. 11), que a "nossa literatura é galho secundário da portuguesa, por sua vez arbusto de segunda ordem no jardim das Musas", chega-se logo à conclusão de que 1880 foi o annus mirabilis das nossas letras, pois a publicação do Brás Cubas superou os nossos "gosto provinciano" e "falta do senso de proporçôes". A mudança de Machado em relação à visão sobre as classes sociais não pode ser a única causa dessa 
revolução artístico-intelectual. Adquirimos uma noção mais rica sobre o fenômeno quando complementamos os estudos de orientação biográficopsicológica com os de orientação histórico-sociológica, contrabalançando sempre as fraquezas e os acertos.

Segundo Schwarz (2012b, p. 40, grifos nossos), o criador do magnum opus da literatura brasileira vale-se do repertório ilustrado internacional apenas com o fim de deformá-lo, mostrando como ele é impropriamente assimilado pela elite brasileira: "A parafernália da retórica e do humanismo, universal por excelência, lhe serve [a Machado], desde que faça figura imprópria, nada universal, com funçôes de lugar e classe historicamente marcadas." Essa leitura, que nulifica a interpretação universalista, náo poderia, de acordo com os pontos de vista sustentados pelo crítico, ser somada à de Eugênio Gomes, que apresenta a irônica retórica machadiana acerca da cultura clássica e humanista como fruto de inspiração no humorismo britânico. A pesquisa das influências inglesas levou Gomes (1976, p. 57) a compreender "que a intenção de Machado de Assis, ao escrever esse livro [Memórias], era a de explorar até às últimas consequências o ridículo de uma ideia fixa atravessada na cabeça de sua personagem." Trata-se, para Gomes (1976, p. 63), em vez de comportamento classista, de "senso de humour que se harmonizava à maravilha com a [...] desenganada filosofia de vida."

Tome-se, por exemplo, o capítulo CXXXVI ("Inutilidade") das Memórias: "Mas, ou muito me engano, ou acabo de escrever um capítulo inútil." (ASSIS, 1975, p. 278). O sentido superficial desse período pode ser logo descartado, afinal, se o capítulo é inútil, por que mantê-lo no romance? Segundo Eugênio Gomes, trata-se de "tendência natural às sentenças concisas e mesmo lacônicas", cujas matérias de reflexão são "pouco ou nada sugestivas para um romancista a sério." Para Schwarz (2000, p. 32-33, grifos do autor), "não se trata de uma disposição passageira, psicológica ou estilística, mas de um princípio rigoroso, sobreposto a tudo, e que portanto se expóe e se pode apreciar em toda linha." Esse "princípio rigoroso", sabemo-lo, é a ideologia de classe, todavia estaria ele "sobreposto a tudo", de modo a inviabilizarem-se outros princípios que poderiam ser identificados?

"Começo a arrepender-me deste livro. Não que ele me canse; eu não tenho que fazer; e, realmente, expedir alguns magros capítulos para esse mundo sempre é tarefa que distrai um pouco da eternidade." (ASSIS, 1975, p. 208). Teríamos aí táo somente uma ironia originária da ociosidade da classe dominante brasileira? Ou o seguinte questionamento de Meyer (1958, p. 212) também é válido: "Que é esta nota amarga, dissimulada em variaçôes humorísticas oscilantes entre a gaiatice e o sarcasmo, senão a manifestação indireta de um imperativo íntimo, de uma espécie de fiat veritas pereat vita?" 
No mesmo ano da publicação de Um mestre, em 1990, houve um debate, no Centro Brasileiro de Análise e Planejamento - CEBRAP, em que os intelectuais Luiz Felipe de Alencastro, Francisco de Oliveira, José Arthur Giannotti, Davi Arrigucci Jr., Rodrigo Naves e José Antonio Pasta Jr. dialogaram com Roberto Schwarz a respeito de seu livro. Somente Giannotti apontou, de fato, problemas na crítica schwarziana acerca das Memórias póstumas, isto é, foi o único a levantar polêmica.

A primeira questão de Giannotti (1991, p. 63) dirigida a Schwarz é a seguinte:

Há uma tese estética no seu livro que está em você desvendar o caráter de classe do Brás Cubas, e, ao desvendar uma verdade da sociedade brasileira, isso serve de parâmetro estético à sua obra. O valor estético da obra é dado pela sua verdade, a ponto de você achar, por exemplo, que existem certas escorregadelas quando esta estrutura não é revelada. [...] Nesse caso a sua tese leva, a meu ver, a uma espécie de paradoxo, isto é, a verdade de uma obra de arte é critério da beleza, mas a beleza pode ser reconhecida, a despeito de ela ser verdadeira ou falsa. Ora, o caso é o seguinte: por que o seu livro não é mais belo que o livro do Machado? Na medida em que é ele que revela a verdade de Brás Cubas.

A réplica de Schwarz (1991, p. 64, grifos nossos) é esta: "Fui procurar a organização do romance do Machado, a razão que torna o Machado particularmente agudo, e descobri [...] que o que dá um mordente particular à ficção dele é um sentimento agudo da injustiça de classe". Assim, Schwarz corrobora a objeçấo de Giannotti: o valor de Brás Cubas não é avaliado por meio de suas qualidades estilístico-composicionais, mas pela dimensão de conhecimento objetivo - a referida verdade - que nele se apresenta. $O$ padrão de julgamento do romance não é estético, pois, se assim o fosse, Schwarz teria de valer-se de critérios também eles artísticos, o que o levaria inevitavelmente a colocar em segundo plano a pesquisa de bases científicas para focalizar os atributos literários que fazem com que as Memórias sejam obra-prima.

Para aferir-se a qualidade artística de uma obra literária, como nos ensina Eliot (1989b), é necessário que o crítico a situe na tradição, isto é, no legado literário que vai de Homero até a contemporaneidade. Os instrumentos científicos permitem-nos perscrutar as camadas de conhecimento científico que um texto literário pode ter, mas a sua função original não é a de abarcar a totalidade do fenômeno artístico, visto que ele contém estratos que transcendem os limites epistemológicos da sociologia, da psicologia, da linguística etc. É por essa razão que a medida de valor da crítica literária encontra-se na própria literatura. Todavia, isolado, o objeto estético não se 
presta à mensurabilidade valorativa, porque a matéria de que é feito encontrase na evoluçấo da história literária. Mostra-nos Eliot (1989b, p. 38) que as causas da criação literária não são metafísicas ou sobrenaturais: o escritor, por meio de um "grande esforço", conquista seu lugar na tradição literária ao ter consciência do monumento formado pelas obras do passado e da necessidade de exprimir-se por intermédio de formas que não sejam iterativas, mas alteradoras desse monumento. $\mathrm{O}$ verdadeiro escritor de literatura é aquele que, de algum modo, altera a tradição, e não se pode alterá-la sem absorvê-la e remodelá-la: "Nenhum poeta, nenhum artista, tem sua significação completa sozinho. Seu significado e a apreciação que dele fazemos constituem a apreciação de sua relaçáo com os poetas e artistas mortos." (ELIOT, 1989b, p. 39).

Por conseguinte, as contribuiçóes científicas podem descortinar a verdade de um livro relativamente à ordem objetiva dos acontecimentos, à História, mas não atingem o sentido totalizante de um objeto cuja natureza, em maior ou menor grau, distancia-se da dimensão factual da vida. É por isso que a comparaçáo, ao lado da análise, como afirma Eliot (1989a, p. 61), é ferramenta fundamental do crítico. Schwarz centra-se na análise e não na comparação. Seu objetivo é a descoberta do veio histórico-sociológico presente na forma das Memórias póstumas, ao passo que Lúcia Miguel Pereira, Augusto Meyer e Eugênio Gomes ativeram-se à posiçáo do romance machadiano na história literária e aos aspectos universais da psicologia humana abordados pelo narrador Brás Cubas.

O ponto nevrálgico é este: ao alegar que só se conhece a verdade do livro à luz da verdade da sociedade brasileira, Schwarz propóe que o objetivo principal de Machado não foi alcançar um lugar na tradição da literatura, mas fazer crítica sociológica. Assim, se o sentido sociológico é o fundamento da beleza do romance, pode-se dizer que o valor do livro é menos literário do que científico. O problema não está na interpretação histórico-sociológica da forma - sempre legítima -, porém no reducionismo da crítica que atribui a grandeza da obra unicamente ao poder de conhecimento social que ela comporta.

Em Ao vencedor as batatas, os narradores machadianos da primeira fase são apresentados por Schwarz como conformistas e conservadores: não questionam a ordem social. Em Um mestre, o crítico evidencia a criação de um narrador que encarna todo o atraso de nosso passado colonial uma técnica literária que teria sido produzida por Machado em sua fase de maturidade para submeter a classe dominante de seu tempo a uma crítica severa. Consequentemente, o juízo estético de Schwarz norteia-se pelo critério político: a obra é boa à medida que contesta, desmascara, critica a forma de organização política vigente, mais propriamente, o conservadorismo. 
Diz Giannotti (1991, p. 65, grifos nossos):

Não há dúvida de que o Roberto encontrou uma chave admirável para entender não só o livro, mas também uma estrutura da intelectualidade brasileira. [...] Essa estrutura [...] privilegia um aspecto central do livro, mas em compensação deixa de lado outro aspecto, que é [...] o lado fantástico do livro, no sentido em que, por exemplo, o delírio e o jogo de aspectos absolutamente solto, que são contrários justamente ao processo de conhecimento, e que você é levado a reduzir a uma falta de conhecimento qualquer. Isto é, há um reducionismo na sua tentativa que eu acho complicado e, mais ainda, você descarta um lado do Machado que [...] está muito ligado a esse pessimismo, que é o lado da melancolia - que é clássica na interpretação do Machado - e essa melancolia náo é tanto o lado de classe, mas é uma melancolia [...] da vanitas, de uma longa tradição do Ocidente que aparece no Machado. Vincular essa melancolia diretamente a uma situação de classe e querer ter esse reducionismo [...] é um problema complicado.

Schwarz (1991, p. 63, primeiros grifos nossos, últimos grifos do autor) reconhece que o seu parâmetro de crítica literária é o coeficiente de verdade:

As belezas sobem e descem, somem, e a maneira de reconhecer e de explicar a beleza, hoje pelo menos, pelo menos na perspectiva em que eu me coloco, é de explicar o que há de substantivo e o que há de profundamente verdadeiro ali. E o escritor em que eu não encontre isso, para mim, para o uso desse tipo de crítica que eu faço, não é bom, não há a menor dúvida.

Entretanto, de fato, há um lado incognoscível em Brás Cubas, uma irracionalidade que o permeia não admitida como tal por Schwarz, que vê nela um recurso literário movido a fins de denúncia social, fins racionais, por assim dizer. Que relação poderia ter o capítulo "O delírio” com o comportamento da classe dirigente brasileira? Escaparia esse capítulo à análise de Schwarz, haja vista, como salientou Giannotti, que ele é construído por meio do "jogo de aspectos absolutamente solto", "contrários justamente ao processo de conhecimento"?

Antes de encaminhar-se "para o undiscovered country de Hamlet" (ASSIS, 1975, p. 100), Brás "relatou o seu próprio delírio" (ASSIS, 1975, p. 108): um hipopótamo o leva à “origem dos séculos" (ASSIS, 1975, p. 108), momento em que ele conhece a "Natureza ou Pandora" (ASSIS, 1975, p. 110), figuras ambíguas: podem representar a onisciência de Deus, a consciência do protagonista a fazer um exame moral da sua trajetória pela vida, o segredo oculto e misterioso das coisas, entre muitas outras possibilidades de interpretação. Essa "figura de mulher" (ASSIS, 1975, p. 110) diz: “- Sim, verme, tu vives. Não receies perder esse andrajo que é teu orgulho; provarás 
ainda, por algumas horas, o pão da dor e o vinho da miséria." (ASSIS, 1975, p. 110). Note-se a finura da reflexão moral: que é o orgulho, para quem se aproxima da morte, senáo um andrajo? Ante a força da Natureza que arrebata impiedosamente a vida, Brás sentia-se "o mais débil e decrépito dos seres" (ASSIS, 1975, p. 110) e tomou ciência da insignificância do homem ao confrontar a história de sua existência com a história da civilização. Afirma a Natureza: “- [...] eu não sou somente a vida; sou também a morte, e tu estás prestes a devolver-me o que te emprestei. Grande lascivo, espera-te a voluptuosidade do nada." (ASSIS, 1975, p. 111). Aqui, o sentimento niilista assombra o herói que passou a vida em busca de prazer.

No trecho seguinte, vê-se a agonia de quem está suspenso ao abismo da morte: “- [...] Não estás farto do espectáculo e da luta? Conheces de sobejo tudo o que eu te deparei menos torpe ou menos aflictivo: o alvor do dia, a melancolia da tarde, a quietação da noite, os aspectos da terra, o sono, enfim, o maior benefício das minhas mãos. Que mais queres tu, sublime idiota?" (ASSIS, 1975, p. 111). Observe-se a figura do humorista, aquele que, segundo Gomes (1958, p. 46), "se critica a si próprio, poupando os outros". Trata-se de humor lúgubre de quem se despede do mundo com tristeza por saber que a morte é o fim dos prazeres e satisfaçóes egoístas.

A construção literária de um universo absurdo e irracional tem a finalidade de mostrar a absurdidade e a irracionalidade da vida: "Para Machado de Assis a natureza é um imenso absurdo" e o episódio do delírio é a narração de uma "intuiçấo delirante do absurdo universal" (MEYER, 1958, p. 32). Não é necessário o conhecimento da História do Brasil monárquico e da sociologia de nossa elite oitocentista para apreender-se o sentido universal de "O delírio", sentido esse poeticamente decifrado por Meyer (1958, p. 33): "O homem essencial que há em nós, além deste saco de vísceras condenado ao apodrecimento, é o ser que deseja ser, o ser que é uma ansiedade infinita de ser."

A volubilidade formal enquanto conduta elitista não é uma forma ubiqua como quer Schwarz (2000, p. 47). A ótica schwarziana amplia o esclarecimento de certas camadas do romance, mas choca-se - ao colocar-se como única interpretação possível - com o discurso fantástico e as notações psicológicas inegavelmente universais. Se adotarmos acriticamente a chave compreensiva arquitetada por Schwarz, teremos de acusar de historicamente alienada a seguinte percepção acerca de "O delírio": "Brás Cubas passa em revista a monotonia da miséria humana - a impressão é a de quem vai caindo num vazio espantoso e na queda goza a volúpia de cair..." (MEYER, 1958, p. 35).

Para Schwarz (2000, p. 32), o relato do delírio do narrador não transmite uma visão pessimista sobre o homem eterno, porém é "um show de cultura 
caricata, uma espécie de universalidade de pacotilha, em que o capricho de Brás Cubas toma como província a experiência global da humanidade e se absolutiza." No entanto, se há, no livro, humor e ironia que envolvem referências universalizantes, muitas vezes servindo ao desígnio de mostrar o seu aspecto jocoso, isso não significa que todas elas sejam manifestaçôes da superficialidade intelectual do rentista abastado que quer assimilar a cultura burguesa europeia e não consegue fazê-lo porque as condiçôes históricas de sua classe são limitantes.

Não queremos afirmar que a interpretação a-histórica é verdadeira e a interpretação histórica é falsa ou vice-versa. Uma postura coerente não fechará a discussão e admitirá a viabilidade de ambos os lados. Quis-se mostrar que a adoção de uma perspectiva restrita, que se sustenta dentro dos limites de um único método, acaba por ocultar dimensóes interpretativas plausíveis de uma obra literária.

\section{Referências}

ASSIS, Machado de. Instinto de nacionalidade. In: ASSIS, Machado de. Crítica. Rio de Janeiro: Garnier, 1910, p. 7-28.

ASSIS, Machado de. Memórias póstumas de Brás Cubas. Edição crítica da Academia

Brasileira de Letras. Rio de Janeiro: Civilização Brasileira; Brasília: Instituto Nacional do Livro, 1975.

BAPTISTA, Abel Barros. Ideia de literatura brasileira com propósito cosmopolita. Revista Brasileira de Literatura Comparada, Niterói, v. 15, p. 61-87, 2009.

CANDIDO, Antonio. Esquema de Machado de Assis. In: CANDIDO, Antonio. Vários escritos. 4. ed. São Paulo: Duas Cidades; Rio de Janeiro: Ouro sobre Azul, 2004. p. 15-32.

CANDIDO, Antonio. Formação da literatura brasileira: momentos decisivos (17501880). 11a. ed. Rio de Janeiro: Ouro sobre Azul, 2007.

ELIOT, Thomas Stearns. A função da crítica. In: ELIOT, Thomas Stearns. Ensaios. Trad. Ivan Junqueira. São Paulo: Art, 1989a, p. 49-62.

ELIOT, Thomas Stearns. Tradição e talento individual. In: ELIOT, Thomas Stearns. Ensaios. Trad. Ivan Junqueira. São Paulo: Art, 1989b, p. 37-48.

GIANNOTTI, José Arthur et al. Machado de Assis: um debate. Conversa com Roberto Schwarz. Novos Estudos CEBRAP, São Paulo, n. 29, p. 59-84, 1991. 
GOMES, Eugênio. Machado de Assis. Rio de Janeiro: São José, 1958.

HOLANDA, Sérgio Buarque de. Originalidade literária. In: HOLANDA, Sérgio Buarque de. O espirito e a letra: estudos de crítica literária I (1920-1947). São Paulo: Companhia das Letras, 1996, p. 35-41.

MELO, Alfredo César Barbosa de. Pressupostos, salvo engano, de uma divergência silenciosa: Antonio Candido, Roberto Schwarz e a modernidade brasileira. Alea - estudos neolatinos, Rio de Janeiro, v. 16, p. 403-420, 2014.

MEYER, Augusto. Machado de Assis (1935-1958). Rio de Janeiro: São José, 1958.

PEREIRA, Lúcia Miguel. Machado de Assis: estudo crítico e biográfico. 6a. ed. Belo Horizonte: Itatiaia; São Paulo: EDUSP, 1988.

SCHWARZ, Roberto. A viravolta machadiana. In: SCHWARZ, Roberto. Martinha versus Lucrécia: ensaios e entrevistas. São Paulo: Companhia das Letras, 2012a. p. 247-279.

SCHWARZ, Roberto. Leituras em competição. In: SCHWARZ, Roberto. Martinha versus Lucrécia: ensaios e entrevistas. São Paulo: Companhia das Letras, 2012 b. p. $9-43$.

SCHWARZ, Roberto. Machado de Assis: um debate. Conversa com Roberto Schwarz. Novos Estudos CEBRAP, São Paulo, n. 29, p. 59-84, 1991.

SCHWARZ, Roberto. Um mestre na periferia do capitalismo: entrevista. In: SCHWARZ, Roberto. Sequências brasileiras: ensaios. São Paulo: Companhia das Letras, 1999, p. 220-226.

SCHWARZ, Roberto. Um mestre na periferia do capitalismo: Machado de Assis. São Paulo: Duas Cidades; Ed. 34, 2000.

WOOD, Michael. Master among the ruins. In: ROCHA, João Cezar de Castro (Org.). The author as plagiarist: the case of Machado de Assis. Massachusetts: University of Massachusetts, 2006, p. 293-303.

Elvis Paulo Couto é doutorando do Programa de Pós-Graduação em Estudos Literários da Faculdade de Ciências e Letras da Universidade Estadual Paulista "Júlio de Mesquita Filho", câmpus de Araraquara.

E-mail: coutoelvis@yahoo.com.br

Recebido em: 15/01/2020

Aceito em: 30/04/2020 